COLORECTAL CANCER

\title{
Monocyte chemoattractant protein 1 and macrophage cyclooxygenase 2 expression in colonic adenoma
}

\author{
S Tanaka, A Tatsuguchi, S Futagami, K Gudis, K Wada, T Seo, K Mitsui, M Yonezawa, \\ K Nagata, S Fujimori, T Tsukui, T Kishida, C Sakamoto
}

See end of article for authors' affiliations

Correspondence to: Professor C Sakamoto, Third Department of Internal Medicine, Nippon Medical School, 1-1-5, Sendagi, Bunkyo-ku, Tokyo, 113-8603, Japan; choitsu@nms.ac.jp

Revised version received 8 June 2005

Accepted for publication 19 July 2005

Published online first

5 August 2005

Background and aims: Cyclooxygenase 2 (COX-2) expression in subepithelial macrophages of colorectal adenoma has been suggested as the first in a series of steps leading to colorectal tumorigenesis. We tested the hypothesis that chemokines released from human colorectal adenoma epithelium might be involved in COX-2 expression in macrophages of the lamina propria.

Methods: Endoscopic samples of sporadic colorectal adenomas were tested by enzyme linked immunosorbent assay for chemokines involved in macrophage chemotaxis. Localisation of adenoma macrophage chemoattractant protein 1 (MCP-1) and COX-2 were determined by immunohistochemistry. The effects of MCP-1, in the presence or absence of celecoxib, on COX-2 expression, and prostaglandin (PG) $E_{2}$ and vascular endothelial growth factor (VEGF) release, were examined in human macrophages isolated from peripheral blood.

Results: MCP-1 levels were markedly higher in adenoma with mild-moderate dysplasia (129.7 (19.9) pg/ $\mathrm{mg}$ protein) and severe dysplasia $(227.9(35.4) \mathrm{pg} / \mathrm{mg}$ protein) than in normal colonic mucosa $(55.8$ (4.2) pg/mg protein). Other chemokine levels, macrophage inflammatory proteins (MIP)- $1 \alpha$ and MIP-1 $\beta$, and the chemokine regulated on activation of normal T cell expressed and secreted (RANTES) did not vary significantly between adenoma and normal mucosa. MCP-1 levels in both adenoma and normal colonic mucosa increased significantly three hours after tissue cultivation in vitro. MCP-1 immunoreactivity was restricted to the adenoma epithelium, with no reactivity seen in adjacent normal epithelial cells. MCP-1 stimulated COX-2 expression and $\mathrm{PGE}_{2}$ and VEGF release in human macrophages. Celecoxib, a selective COX-2 inhibitor, inhibited MCP-1-induced $\mathrm{PGE}_{2}$ and VEGF release in macrophages. Addition of exogenous $\mathrm{PGE}_{2}$ reversed this inhibitory effect on VEGF release, suggesting that MCP-1 in adenoma epithelial cells might be involved in COX-2 expression and subsequent macrophage activation.

Conclusions: MCP-1 in colorectal adenoma epithelial cells might be involved in macrophage migration and COX-2 expression, leading to the subsequent development of colonic adenoma.

E pidemiological studies have shown that subjects on a regimen of aspirin or other non-steroidal anti-inflammatory drugs (NSAIDs) known to inhibit cyclooxygenase (COX) activity have a reduced risk of developing colon cancer. ${ }^{1-4}$ In addition, recent clinical randomised trials have shown the therapeutic value of aspirin both in the prevention of colorectal cancer ${ }^{5}$ and its recurrence. ${ }^{78}$ Studies have also shown that NSAIDs decrease the size and number of polyps in patients with familial adenomatous polyposis (FAP). ${ }^{10}$ COX-2 has been found to be expressed not only in interstitial cells infiltrating human colorectal adenoma and cancer tissue but also in cancer cells themselves. ${ }^{11}$ However, recent studies have shown that at the onset of tumorigenesis in the colon, COX-2 expression is limited to macrophages localised just beneath epithelial cells of polyps in APC716 knockout mice, an animal model of human FAP, and in the subepithelium of mild dysplasia human adenoma. ${ }^{12-15}$ Also, COX-2 gene knockout or administration of selective COX-2 inhibitors have been shown to decrease the number and size of intestinal polyps in APC716 mice. ${ }^{14}{ }^{15}$ These data suggest that COX-2 expressed in macrophages plays a crucial role in adenoma growth and its progression to colon cancer. Recent studies also show intense vascularisation in interstitial areas populated with COX-2 positive macrophages, ${ }^{16}$ suggesting a possible functional relationship between macrophage COX-2 expression and angiogenesis. However, the mechanisms through which macrophages infiltrate into the lamina propria at the epithelial border, and express COX-2, have yet to be determined in adenoma of the colon.

The high macrophage density in tumours of the colon is thought to be primarily maintained by recruitment of circulating monocytes. Most members of the -CC chemokine family, including macrophage chemoattractant protein (MCP)-1, macrophage inflammatory proteins (MIP)- $1 \alpha$ and MIP-1 $\beta$, and the chemokine regulated on activation of normal $\mathrm{T}$ cell expressed and secreted (RANTES), have macrophage chemoattractant properties, ${ }^{17}$ with MCP-1 being one of the most potent macrophage recruiters. ${ }^{18}$ Moreover, studies have suggested that MCP-1 expressed in colonic epithelial cells plays a role in modulating immune responses in inflamed colonic mucosa. ${ }^{19}$

Abbreviations: COX-2, cyclooxygenase 2; MCP-1, macrophage chemoattractant protein; PG, prostaglandin; VEGF, vascular endothelial growth factor; RANTES, regulated on activation of normal T cell expressed and secreted; ELISA, enzyme linked immunosorbent assay; MIP, macrophage inflammatory protein; NSAIDs, non-steroidal antiinflammatory drugs; FAP, familial adenomatous polyposis; $\mathrm{H} \& \mathrm{E}$, haematoxylin and eosin; PBS, phosphate buffered saline; EDTA, ethylenediaminetetraacetic acid; PMSF, phenylmethylsulfonyl fluoride; FITC, fluorescein isothiocyanate; PBMC, peripheral blood mononuclear cells; FCS, fetal calf serum; LPS, lipopolysaccharide; CHAPS, 3[(3,cholamidopropyl)-dimethylammonio]-I-propane-sulfonate 
Thus we hypothesised that -CC chemokines released from epithelial cells in colonic adenoma might be involved in macrophage migration, COX-2 expression in these migrant macrophages and, thereby, in the evolution of colonic adenoma into tumorigenesis. In this study, we investigated expression of various macrophage chemotactic factors in human colorectal adenomas and examined the effect of MCP-1 on COX-2 expression, prostaglandin (PG) $\mathrm{E}_{2}$ release, and vascular endothelial growth factor (VEGF) production in human macrophages.

\section{MATERIALS AND METHODS Patients and tissue specimens}

Tissue samples were obtained from 156 patients (105 males, 51 females; median age 69.84 years; age range $40-88$ ) who had undergone colonoscopy due to altered bowel habits or abdominal pain, at the Department of Internal Medicine, Nippon Medical School, Tokyo, Japan. We collected one colonic adenoma sample by endoscopic polypectomy and one adjacent normal colonic mucosa biopsy sample per patient. Adenomas and normal mucosa from patients with inflammatory bowel disease or FAP were excluded from this study. Adenoma tissue samples were fixed in 10\% formalin and embedded in paraffin. Sections were prepared, stained with haematoxylin and eosin (H\&E), and analysed immunohistochemically. Specimens were diagnosed and grade of dysplasia classified according to the WHO classification by expert pathologists. Specimens not diagnosed as adenomas were excluded. Finally, we used 10 adenoma samples each for mild-moderate or severe dysplasia adenomas, and 10 normal colonic mucosa samples from areas adjacent to each of these adenoma types per chemokine analysis of MCP-1, RANTES, MIP- $1 \alpha$, and MIP- $1 \beta$. We also used 10 additional adenoma samples for short term tissue cultivation. Before examination, the protocol was fully explained to all subjects and written informed consent was obtained.

\section{Chemokine assays}

Adenoma tissue samples were homogenised with phosphate buffered saline (PBS) at pH 7.4 containing $2 \mathrm{mmol} / \mathrm{l}$ ethylenediaminetetraacetic acid (EDTA), $1 \mathrm{mmol} / \mathrm{l}$ pepstatin A (Sigma Chemical Co, St. Louis, Missouri, USA), and $1 \mathrm{mmol} / \mathrm{l}$ phenylmethylsulfonyl fluoride (PMSF) (Sigma Chemical Co.). Samples were centrifuged at $10000 \mathrm{~g}$ for 15 minutes at $4^{\circ} \mathrm{C}$ and supernatants used for subsequent chemokine analysis. Briefly, $200 \mu \mathrm{l}$ aliquots of each supernatant were added to enzyme linked immunosorbent assay (ELISA) plates coated with MCP-1 antibody (R\&D Systems, Minneapolis, Minnesota, USA) and incubated at room temperature for two hours, and then for an additional 30 minutes with the secondary antibody against MCP-1. After colour development, we measured absorbance at $450 \mathrm{~nm}$ for MCP-1. For each adenoma polyp and normal mucosa, RANTES, MIP- $1 \alpha$, and MIP-1 $\beta$ concentrations were also quantified as per instructions in the respective ELISA kits (MIP- $1 \alpha$, MIP- $1 \beta$, and RANTES; R\&D Systems). Total protein concentration was also evaluated using the protein assay system (Bio-Rad Laboratories, Hercules, California, USA). Bovine serum albumin (Seikagaku Kogyo, Tokyo, Japan) was used as standard. Chemokine concentrations are expressed as pg per $\mathrm{mg}$ protein. For each grade of adenoma dysplasia, we compared adenoma chemokine levels with those of normal mucosa from the same patient.

\section{Adenoma tissue culture}

To verify that adenoma tissue synthesises chemokines, 10 adenoma and 10 normal colonic mucosa tissue samples were washed twice with PBS immediately after endoscopic polypectomy and then cultured in RPMI-1640 (Nikken,
Kyoto, Japan) for three hours at $37^{\circ} \mathrm{C}$. Residual tissue samples were fixed, stained with $\mathrm{H} \& \mathrm{E}$, and analysed immunohistochemically. After three hours of cultivation, tissue samples were homogenised and supernatants used for chemokine analysis, as described above.

\section{Immunofluorescence analysis of human sporadic colonic adenoma}

Double immunofluorescence analysis and confocal laser scanning microscopy were used to evaluate colocalisation of COX-2 (diluted 1:5; IBL, Gunma, Japan) and MCP-1 (diluted 1:10; PePro Tech, Rocky Hill, New Jersey, USA). Sections were incubated overnight at $4^{\circ} \mathrm{C}$ with a mixture of the two primary antibodies. The antibody against COX-2 was allowed to react with a secondary antibody (goat antirabbit IgG; diluted 1:100; Vector Laboratories, Burlingame, California, USA) labelled with Texas red. The antibody against MCP-1 was allowed to react with a secondary antibody (horse antimouse IgG; diluted 1:100; Vector) labelled with fluorescein isothiocyanate (FITC; Sigma Chemical Co.), followed by nuclear counterstaining with 4', 6-diamidino-2-phenylindole (Sigma Chemical Co.) for 15 minutes to facilitate identification of morphological features.

Sections were also incubated with antihuman COX-2 and anti-CD68 (Dako, Kyoto, Japan) antibodies (both diluted $1: 25$ in PBS) and followed by incubation with Texas red conjugated horse antimouse immunoglobulin G (IgG; CD68; Vector) and FITC conjugated goat antirabbit IgG (COX-2; Vector) for 60 minutes at room temperature. Immunofluorescence was analysed under a laser scanning confocal fluorescence microscope (Leica TCS-4D DMIRBE, Heidelberg, Germany), equipped with argon and argonkrypton laser sources.

\section{Isolation of monocytes from human blood}

Peripheral blood was collected from volunteer donors. Peripheral blood mononuclear cells (PBMC) were isolated from human blood samples by Ficoll-Paque (Phamacia Biotech, Uppsala, Sweden) centrifugation. PBMCs $\left(2 \times 10^{6} \%\right.$ $\mathrm{ml}$ ) were seeded onto six well plates, incubated in RPMI1640 supplemented with non-essential amino acids, $2 \mathrm{mmol} / \mathrm{l}$ sodium pyruvate, $2 \mathrm{mmol} / \mathrm{L}$-glutamine, $0.1 \% \mathrm{NaHCO}_{3}, 50 \mu \mathrm{g} /$ $\mathrm{ml}$ streptomycin (Gibco-BRL, Gaithersburg, Maryland, USA), $50 \mathrm{U} / \mathrm{ml}$ penicillin (Gibco-BRL), and 2\% fetal calf serum (FCS; Trace Laboratories, Palatine, Illinois, USA) overnight, and adherent cells allowed to differentiate into macrophages. Monocytes comprised over $85 \%$ of these cells, as shown by CD68 staining, and had a viability $>90 \%$, as indicated by Trypan blue dye exclusion tests. These cells were stimulated with $10 \mathrm{ng} / \mathrm{ml} \mathrm{MCP-1}$ for 24 hours in the presence of FCS, and then harvested and stored at $-70^{\circ} \mathrm{C}$ for western blot analysis. Supernatants were harvested for $\mathrm{PGE}_{2}$ and VEGF measurements.

\section{PBMC preparation for immunocytochemical analysis} Human macrophages $\left(2 \times 10^{6} / \mathrm{ml}\right)$ were plated onto two well Laboratory-Tek chamber slides (Nalge Nunc Intl, Naperville, Illinois, USA). After 24 hours of incubation, with or without $10 \mathrm{ng} / \mathrm{ml} \mathrm{MCP}-1$, cells were fixed in 4\% paraformaldehyde for 10 minutes at room temperature and then permeabilised with methanol for 20 minutes at $4^{\circ} \mathrm{C}$. Cells were then incubated with anti-CD68 (Novocastra Laboratories, Newcastle, UK) and anti-COX-2 antibodies, and double immunofluorescence was analysed as described above.

MCP-1 stimulation of PBMC and measurement of PGE2 and VEGF

PBMC were seeded onto each well of six well plates or onto $10 \mathrm{~cm}$ dishes at a density of $2 \times 10^{6}$ cells $/ \mu \mathrm{l}$ in either $1 \%$ or 



Figure 1 Chemokine concentrations in human sporadic adenomas of the colon. Adenoma samples were categorised by degree of dysplasia after pathological examination. Ten samples each of mild-moderate or severe dysplasia were randomly assigned for measurement of each chemokine: (A) macrophage chemoattractant protein 1 (MCP-1); (B) regulated on activation of normal T cell expressed and secreted (RANTES); (C) macrophage inflammatory protein (MIP)- $1 \alpha$; and (D) MIP-1 $\beta$. Horizontal bars indicate mean values. The amount of each chemokine was compared with that of normal colonic mucosa taken from the same subject. ${ }^{*} \mathrm{p}<0.05,{ }^{* *} \mathrm{p}<0.005$

$10 \%$ FCS culture medium. Cells were incubated for 24 hours with either $20 \mathrm{ng} / \mathrm{ml}$ lipopolysaccharide (LPS) or $10 \mathrm{ng} / \mathrm{ml}$ MCP-1 (Santa Cruz Biotechnology, Inc, Santa Cruz, California, USA) in the presence of $1 \%$ or $10 \%$ FCS. Thereafter, culture supernatants were used to measure $\mathrm{PGE}_{2}$ and VEGF concentrations according to instructions in commercially available kits (PGE2: Assay Designs Inc., Ann Arbor, Michigan, USA; VEGF: Biosource, Camarillo, California, USA), as we have shown recently in human gastric fibroblasts. ${ }^{20}$ In experiments with COX inhibitors, either $200 \mathrm{nmol} / \mathrm{l}$ SC560 (Pharmacia, Newark, New Jersey, USA) or $10 \mu \mathrm{mol} / \mathrm{l}$ celecoxib (Pharmacia), selective COX-1 and COX-2 inhibitors, respectively, were added one hour before MCP-1 stimulation in the presence or absence of $\mathrm{PGE}_{2}$ (Sigma-Aldrich, St Louis, Missouri, USA). Previous studies have shown that SC560 at $100-300 \mathrm{nmol} / \mathrm{l}$ reduces $\mathrm{PGE}_{2}$ release according to dose, without affecting COX-2 dependent PGE 2 production. ${ }^{21}$ Thus we used SC560 at $200 \mathrm{nmol} / \mathrm{l}$ in the present study. Celecoxib $10 \mu \mathrm{mol} / \mathrm{l}$ has been shown to inhibit COX-2 dependent $\mathrm{PGE}_{2}$ production by $>90 \%$ without affecting cell viability. ${ }^{22}$

\section{Western blot analysis of COX-1 and COX-2 proteins in human macrophages}

COX protein in human macrophages was partially purified, as previously reported by Mizuno and colleagues. ${ }^{23}$ Macrophages were homogenised in $50 \mathrm{mmol} / \mathrm{l}$ Tris HCL ( $\mathrm{pH} 8.0), 0.5 \mathrm{~mol} / \mathrm{l}$ sucrose containing $1.0 \mathrm{mmol} / \mathrm{l} \mathrm{PMSF}, 1.0 \mathrm{mmol} / \mathrm{l}$ pepstatin A, and $2.0 \mathrm{mmol} / \mathrm{l}$ EDTA. CHAPS (3-[(3, cholamidopropyl)dimethylammonio]-l-propane-sulfonate) (Sigma Chemicals) was added to $1 \%(\mathrm{wt} / \mathrm{vol})$, and the mixture stirred for two hours at $4^{\circ} \mathrm{C}$. After 10 minutes of centrifugation at $15000 \mathrm{~g}$, the supernatant was loaded onto an anion exchange column equilibrated with $25 \mathrm{mmol} / \mathrm{l}$ Tris HCL ( $\mathrm{pH} \mathrm{8.0)}$ ) plus $0.4 \%$ CHAPS. The fraction eluted at $500 \mathrm{mmol} / \mathrm{l} \mathrm{NaCl}$ was concentrated to $40 \%$ of the initial volume. Samples were separated by sodium dodecyl sulphate-polyacrylamide gel

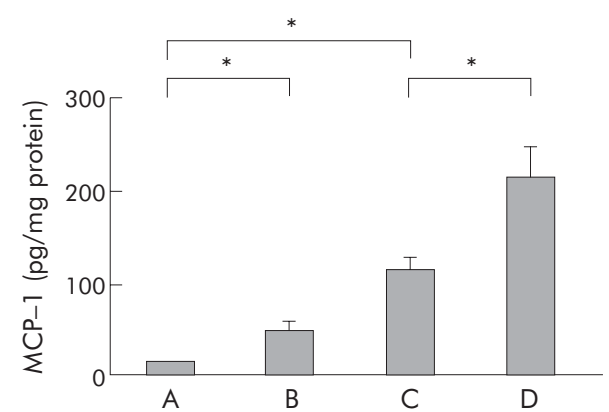

Figure 2 Macrophage chemoattractant protein 1 (MCP-1) synthesis in adenoma tissue and normal colonic mucosa cultured in vitro. MCP-1 concentration was compared between adenoma tissue and normal mucosa from the same patients before and after three hours of tissue cultivation. (A) Normal mucosa before cultivation; (B) normal mucosa after three hours of cultivation; (C) adenoma tissue before cultivation; and (D) adenoma tissue after three hours of cultivation. MCP-1 levels in both adenoma and normal colonic mucosa significantly increased during three hours of cultivation. Each column indicates mean (SEM) of 10 tissue samples. ${ }^{*} p<0.05$.

electrophoresis and transferred onto a Hybond-P nitrocellulose membrane (Amersham Life Science, Buckinghamshire, UK) and probed with anti-COX-1 or anti-COX-2 antibody (diluted 1:50, 1:100). Bound antibodies were detected with horseradish peroxidase conjugated antirabbit IgG (diluted 1:2000) using the enhanced chemiluminescence detection system (Amersham Biosciences). Protein concentration was measured with protein assay reagent.

\section{Statistical analysis}

Data are presented as means (SEM). The paired $t$ test was used for comparison of chemokine assays for normal colonic mucosa and adenomas in the same patients. $\mathrm{PGE}_{2}$ and VEGF levels released from human macrophages were analysed by 

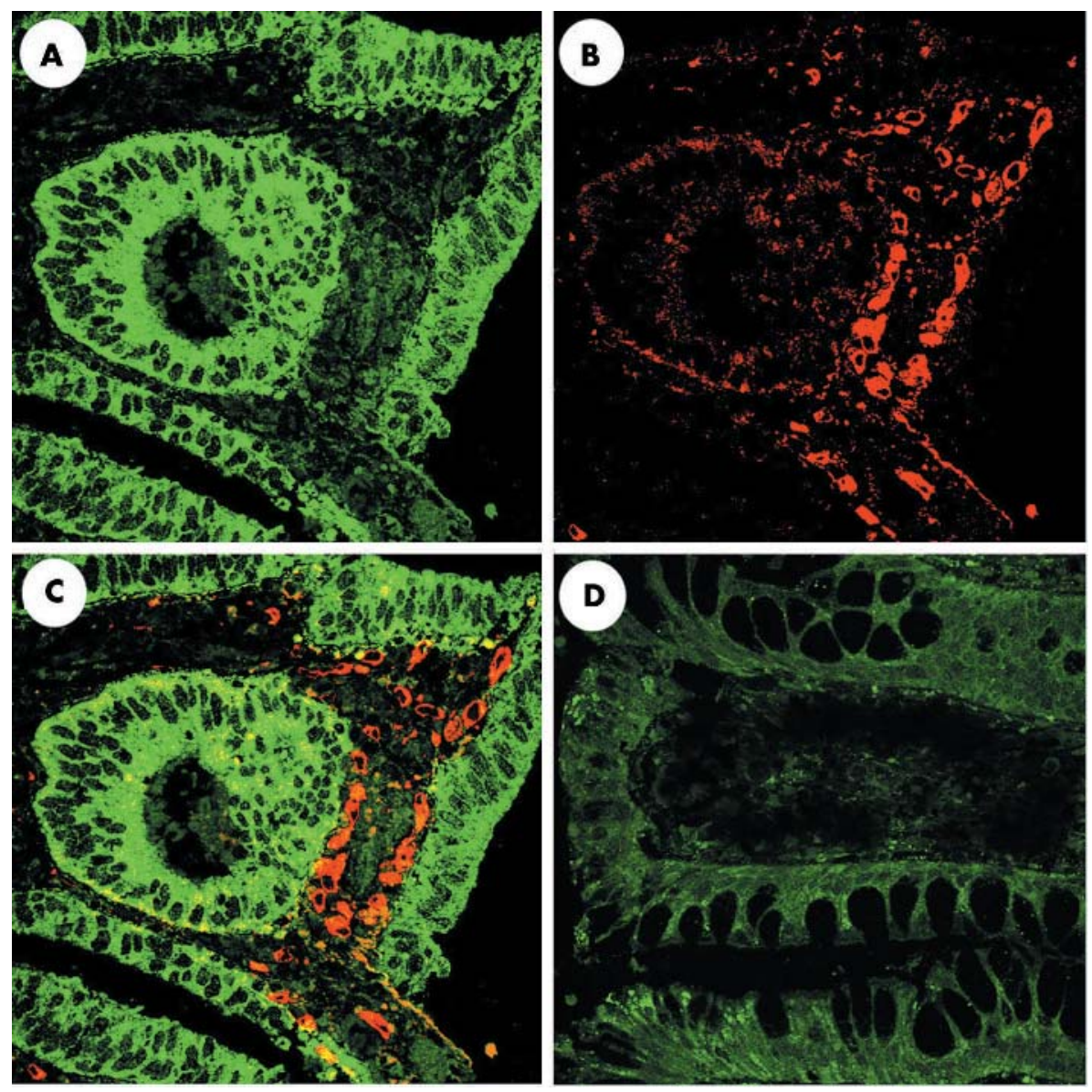

Figure 3 Immunofluorescence staining for macrophage chemoattractant protein 1 (MCP-1) and cyclooxygenase 2 (COX-2) expression in human sporadic adenoma. Five adenoma tissue samples each with mild to moderate dysplasia or severe dysplasia were used for immunofluorescence analysis. Each panel shows a representative adenoma tissue with mild to moderate dysplasia. The same section was stained for MCP-1 (A) and COX-2 (B). Merged image of this staining is shown in (C). Merged image of normal colonic mucosa stained for MCP-1 and COX-2 is shown in (D).

the non-parametric Mann-Whitney test. The software program Statview was used for data analysis. A p value $<0.05$ was regarded as statistically significant.

\section{RESULTS}

Chemokine levels in human sporadic colonic adenoma We measured levels of MCP-l, RANTES, MIP- $1 \alpha$, and MIP-1 $\beta$, all chemokines potentially involved in the migration of macrophages into the subepithelium of colonic adenoma. After pathological examination, each chemokine level was measured in 20 adenoma samples, 10 each for adenomas with mild-moderate or severe dysplasia. Each adenoma sample was matched with its corresponding normal colonic mucosa sample, taken from the same patient, and chemokine levels compared. MCP-1 levels were significantly higher in adenoma than in normal colonic mucosa $(55.8$ (4.2) pg/mg protein), with higher levels seen in samples of colonic adenoma with severe dysplasia (227.9 (35.4) pg/mg protein) than in those with mild-moderate dysplasia (129.7 (19.9) pg/ mg protein) (fig lA). However, there were no significant differences in chemokine levels for RANTES, MIP-l $\alpha$, or MIP-1 $\beta$ for all groups tested (fig 1B-D).

MCP-1 synthesis in adenoma tissue cultured in vitro To verify that elevated MCP-1 levels are derived from the adenoma itself, and not from the peripheral circulation, we cultured adenoma tissue for a brief period and compared MCP-1 levels before and after cultivation.
In this experiment, all but one tissue sample was identified as mild to moderate dysplasia by subsequent H\&E analysis of residual tissue samples. Thus nine mild to moderate dysplasia samples were used for the present analysis. MCP-1 levels in both adenoma and normal colonic mucosa significantly increased during three hours of cultivation. These increases were in proportion to basal levels of each tissues type, suggesting that MCP-1 is not derived from the peripheral circulation, but actually synthesised by colonic adenoma themselves (fig 2).

Immunofluorescence analysis of MCP-1 and COX-2 in human sporadic colonic adenoma

Next we examined the immunohistological localisation of MCP-1 and COX-2 in colonic adenoma and normal mucosa. Neither COX-2 nor MCP-1 immunoreactivities were seen in normal colonic mucosa (fig 3D). In contrast, MCP-1 reactivity was detected in the cytoplasm of epithelial cells in both mild to moderate and severe dysplasia adenomas, whereas COX-2 reactivity was detected in stromal cells at the upper border of the lamina propria, just beneath the epithelium of colonic adenomas (fig $3 \mathrm{~A}-\mathrm{C}$ ). Figure 3 shows a representative immunofluorescence analysis of adenomas with mild to moderate dysplasia. Although localisation of MCP-1 and COX-2 expression did not vary significantly between mildmoderate and severe dysplasia adenomas, only weak COX-2 expression was seen in epithelial cells of the latter (data not shown). 

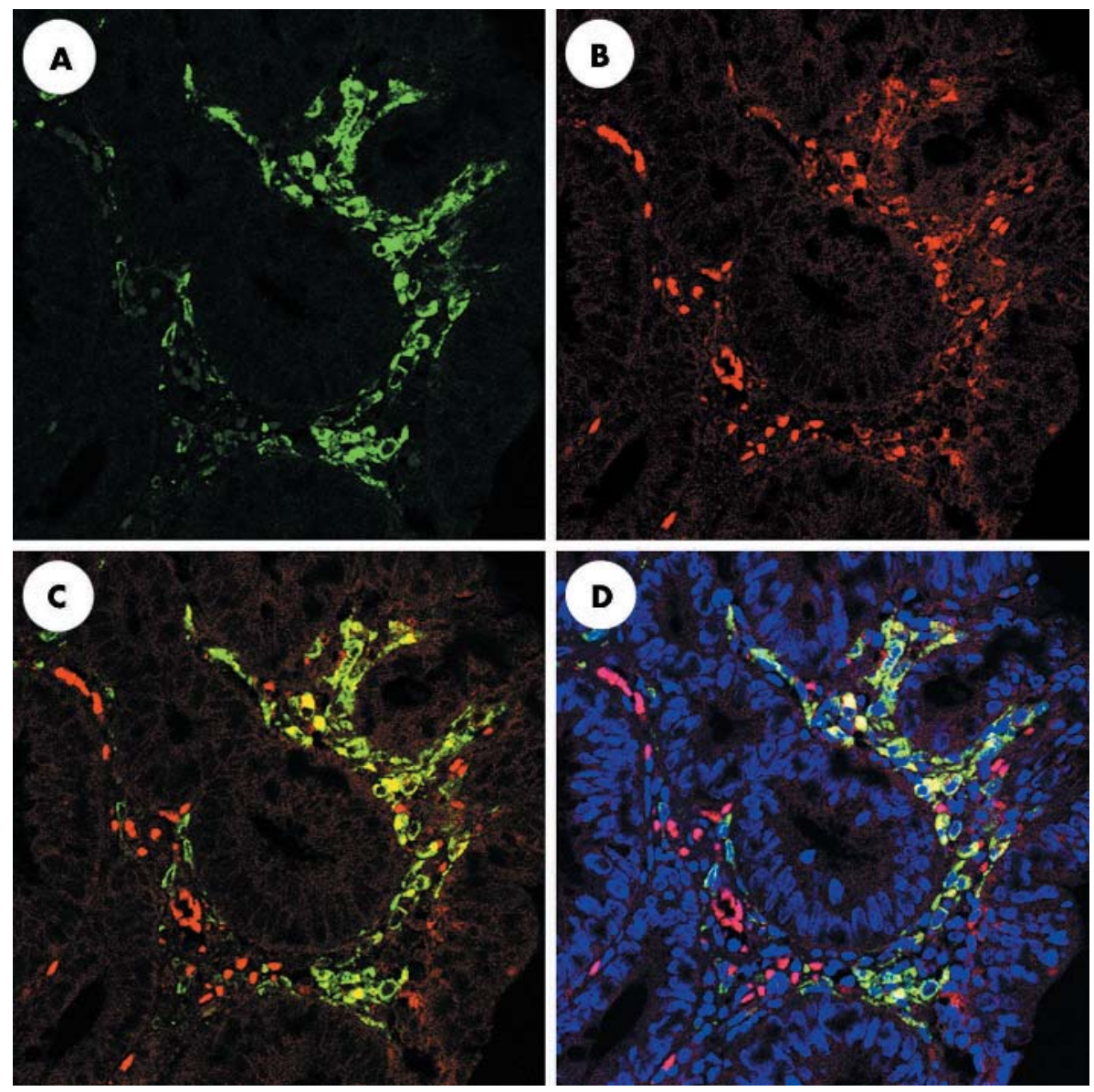

Figure 4 Colocalisation of cyclooxygenase 2 (COX-2) and CD68 in human sporadic colorectal adenoma by dual labelling immunofluorescence. Five adenoma tissue samples each with mild to moderate dysplasia or with severe dysplasia were used for immunofluorescence analysis. Each panel shows a representative adenoma tissue with mild to moderate dysplasia. (A) Numerous COX-2-positive interstitial cells. (B) CD68 positive macrophages. (C) Colocalisation of COX-2 and CD68 using a dual wavelength filter. (D) 4', 6-diamidino-2-phenylindole staining emphasises localisation of COX-2 and CD68 dual stained cells.

Immunohistological colocalisation of CD68 and COX-2 in human sporadic colonic adenoma

To examine the possibility that, in colonic adenoma, macrophages express COX-2 in the subepithelium, we performed dual immunohistochemical analysis of COX-2 and CD68 expression in macrophages. Single immunofluorescence in adenomas with mild to moderate dysplasia showed numerous interstitial CD68 positive cells (fig 4A)

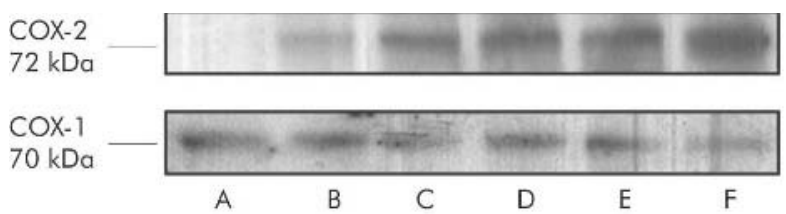

Figure 5 Western blot analysis showing expression of cyclooxygenase 2 (COX-2) in human macrophages stimulated by macrophage chemoattractant protein 1 (MCP-1). Lower and upper panels indicate COX-1 and COX-2 expression, respectively. Macrophages were incubated for 24 hours: (A) without stimulation; (B) with $1 \mathrm{ng} / \mathrm{ml}$ MCP-1; (C) with $10 \mathrm{ng} / \mathrm{ml} \mathrm{MCP-1;} \mathrm{(D)} \mathrm{with} 10 \mathrm{ng} / \mathrm{ml} \mathrm{MCP-1,} \mathrm{one} \mathrm{hour}$ after $10 \mu \mathrm{mol} / \mathrm{l}$ celecoxib pretreatment; (E) with $10 \mathrm{ng} / \mathrm{ml} \mathrm{MCP-1}$, one hour after $200 \mathrm{nmol} / \mathrm{I}$ SC560 pretreatment; and (F) with $20 \mathrm{ng} / \mathrm{ml}$ lipopolysaccharide as a positive control. Thereafter, macrophages were homogenised and western blot analysis was performed as described in materials and methods. and a smaller number of interstitial COX-2 positive cells (fig 4B). Dual fluorescence analysis showed COX-2 protein expression largely limited to a subgroup of CD68 positive macrophages (fig 4C-D).

\section{COX-1 and COX-2 expression in MCP-1 stimulated human macrophages}

We then examined the effect of MCP-1 on COX-1 and COX-2 expression in human macrophages prepared from PBMC, as described in materials and methods. MCP- 1 at 1 and $10 \mathrm{ng} / \mathrm{ml}$ stimulated macrophage COX-2 protein expression according to dose, with no effect on COX-1 expression (fig 5). COX-2 expression levels stimulated by $10 \mathrm{ng} / \mathrm{ml}$ MCP-1 for 24 hours paralleled those of COX-2 expression stimulated by $20 \mathrm{ng} / \mathrm{ml}$ LPS. Neither COX-2 nor COX-1 inhibitors had any effect on COX-2 expression levels stimulated by $10 \mathrm{ng} / \mathrm{ml}$ MCP- 1 .

\section{Immunofluorescence analysis of anti-CD68 and COX- 2 antibodies in human macrophages}

Although our preparations of human peripheral macrophages were highly purified, contamination by other mononuclear cells present in PBMC could not be avoided. We thus examined whether COX-2 protein induced by MCP-1 stimulation was limited to macrophages, using immunofluorescence staining with anti-COX-2 and anti-CD68 antibodies. When the macrophage preparation was stimulated with $10 \mathrm{ng} / \mathrm{ml}$ MCP-1 for 24 hours, no variation was seen in 

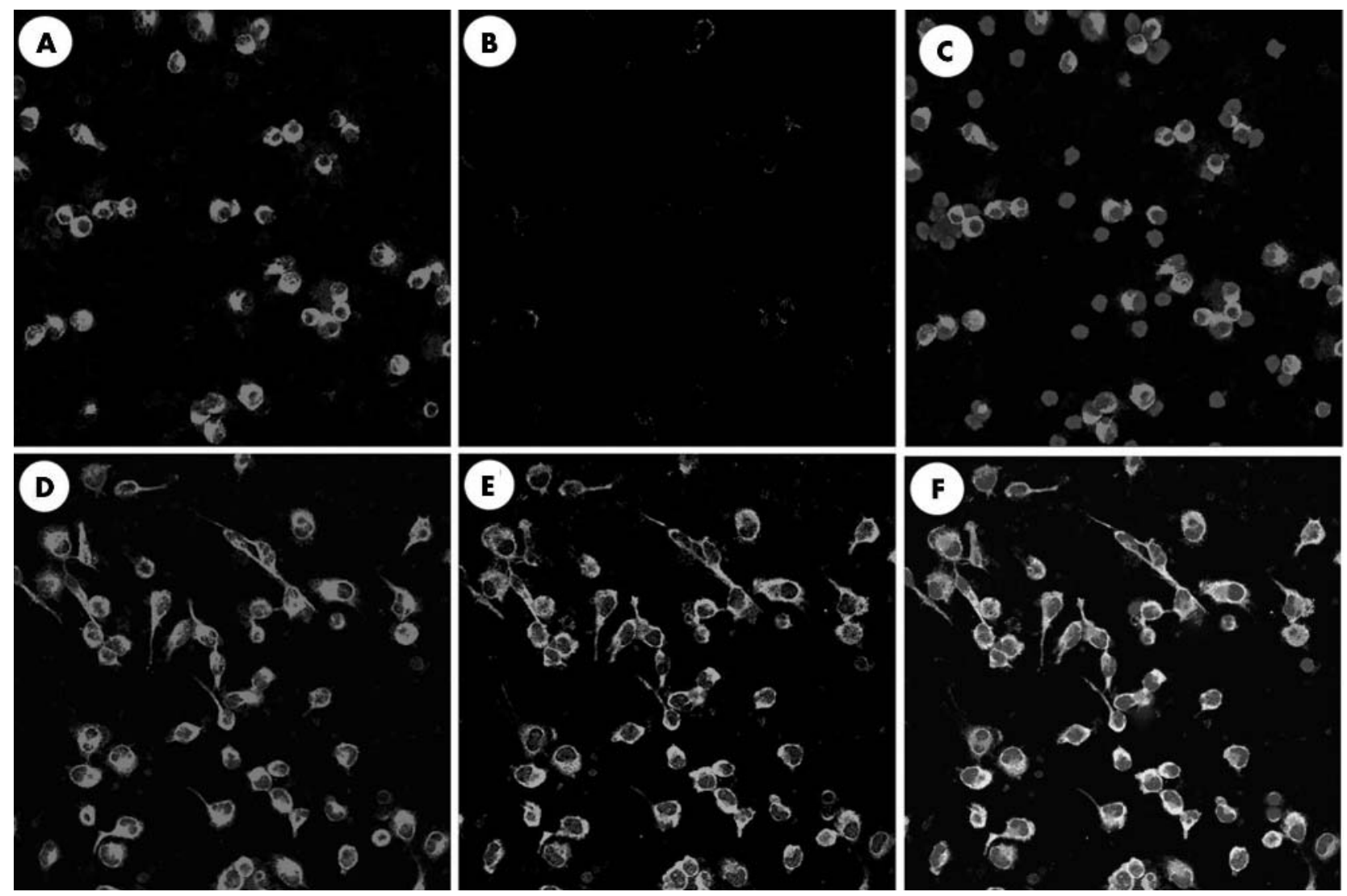

Figure 6 Immunofluorescence staining of peripheral blood mononuclear cells (PBMCs) cultured in the presence of macrophage chemoattractant protein 1 (MCP-1). CD68 staining of PBMCs after 24 hours of culture without (A) or with (D) $10 \mathrm{ng} / \mathrm{ml} \mathrm{MCP-1} \mathrm{stimulation,} \mathrm{as} \mathrm{well} \mathrm{as} \mathrm{cyclooxygenase} 2$ $(C O X-2)$ staining without (B) or with (E) MCP-1 stimulation. Merged image of $(A)$ and (B) is shown in (C). Merged image of (D) and (E) is shown in (F). 4 ', 6-diamidino-2-phenylindole staining is seen in (C) and (F).

the number or shape of CD68 positive cells, although COX-2 positive staining increased to include $\sim 90 \%$ of cultured cells. Double immunostaining clearly showed that all CD68 positive cells expressed COX-2 protein (fig 6), suggesting that cultured macrophages expressed $\mathrm{COX}-2$ protein on MCP-1 stimulation.

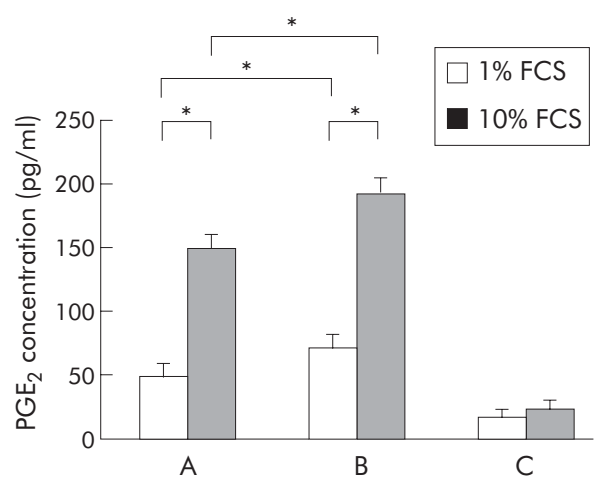

Figure 7 Prostaglandin (PG) $E_{2}$ concentration in supernatant of macrophages isolated from peripheral blood mononuclear cells (PBMCs). PBMCs were cultured in 1\% fetal calf serum (FCS) or 10\% FCS for 24 hours. PGE 2 levels in: (A) culture supernatant of PBMCs without stimulation; (B) with $10 \mathrm{ng} / \mathrm{ml}$ macrophage chemoattractant protein 1 (MCP-1) stimulation; (C) with $10 \mathrm{ng} / \mathrm{ml}$ MCP-1 stimulation after one hour of $10 \mu \mathrm{mol} / \mathrm{l}$ celecoxib pretreatment. Results are shown as mean (SEM) in a representative of three separate experiments. The error bar indicates the standard error calculated from triplicate samples in a representative experiment. ${ }^{*} \mathrm{p}<0.05$.

\section{$\mathrm{PGE}_{2}$ release from human $\mathrm{MCP}$ - 1- stimulated macrophages}

Next we measured $\mathrm{PGE}_{2}$ release from macrophages isolated from PMBC in response to MCP-1 by enzyme immunoassay. Macrophages were stimulated with $10 \mathrm{ng} / \mathrm{ml} \mathrm{MCP-1}$ in the presence of either $1 \%$ or $10 \%$ FCS, where $\mathrm{PGE}_{2}$ release increased with FCS concentration even in the absence of MCP-1 (48.3 (10.4) v 150.0 (10.0) pg/ml; p<0.05). However, MCP-1 at $10 \mathrm{ng} / \mathrm{ml}$ further stimulated $\mathrm{PGE}_{2}$ release even in the presence of 10\% FCS (150.0 (10.0) $v 193.3$ (11.5) pg/ml; $\mathrm{p}<0.05$ ). Celecoxib at $10 \mu \mathrm{mol} / \mathrm{l}$ significantly inhibited $\mathrm{PGE}_{2}$ release down to levels below those induced by $1 \%$ FCS alone (fig 7). These results suggest that MCP-1 or FCS stimulated $\mathrm{PGE}_{2}$ release was dependent on COX-2.

\section{VEGF release in human MCP-1-stimulated macrophages}

We then measured VEGF levels in these cultured media by ELISA. MCP-1 $10 \mathrm{ng} / \mathrm{ml}$ significantly stimulated VEGF release from human cultured macrophages (1119.3 (38.4) $v$ 1301.0 (22.7) pg/ml; p<0.05). Celecoxib significantly suppressed MCP-1-stimulated VEGF release (1017.6 (76.7) pg/ $\mathrm{ml} ; \mathrm{p}<0.05$ ), and $\mathrm{PGE}_{2}$ reversed this inhibitory effect according to dose $\left(1559.3\right.$ (56.1) $\mathrm{pg} / \mathrm{ml}$, with $\mathrm{PGE}_{2}$ at a concentration of $100 \mu \mathrm{mol} / \mathrm{l} ; \mathrm{p}<0.05$ ) (fig 8). Celecoxib did not affect MCP-1-stimulated COX-2 expression (fig 5) and $\mathrm{PGE}_{2}$ reversed the inhibitory effect of celecoxib on VEGF release, suggesting that the inhibitory effect of celecoxib seen in the present study is not due to its toxic effect on macrophages. Therefore, our results suggest a domino effect initiated by MCP-1 stimulation of COX-2 expression in 


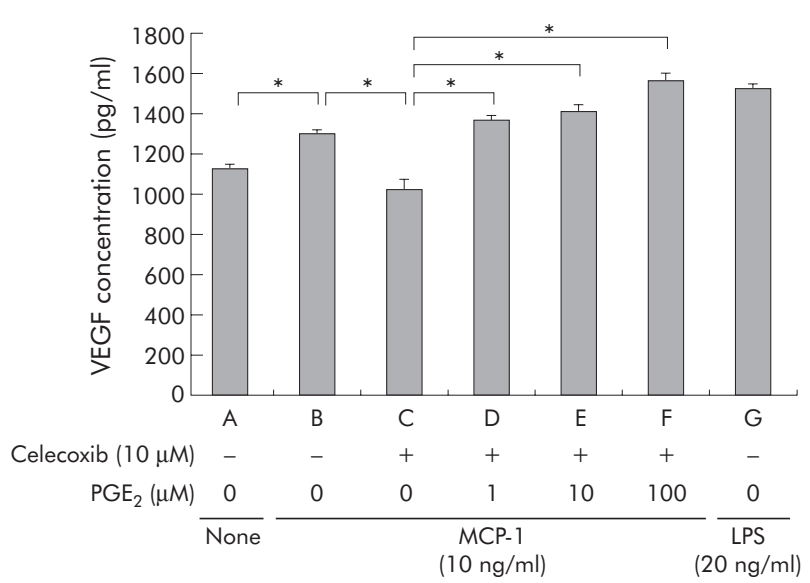

Figure 8 Vascular endothelial growth factor (VEGF) levels in supernatants of macrophages isolated from peripheral blood mononuclear cells (PBMCs). PBMCs were incubated with or without macrophage chemoattractant protein 1 (MCP-1) stimulation in the presence of $10 \%$ fetal calf serum for 24 hours. Each column indicates VEGF levels in culture PBMC supernatants without stimulation $(A)$, with $10 \mathrm{ng} / \mathrm{ml} \mathrm{MCP-1} \mathrm{stimulation} \mathrm{(B),} \mathrm{and} \mathrm{with} 10 \mathrm{ng} / \mathrm{ml}$ MCP-1 stimulation, one hour after pretreatment with $10 \mu \mathrm{mol} / /$ celecoxib (C). In addition, prostaglandin (PG) $E_{2}$ at concentrations of $1 \mu \mathrm{mol} / \mathrm{l}(D), 10 \mu \mathrm{mol} / \mathrm{I}(E)$, and $100 \mu \mathrm{mol} / \mathrm{I}$ (F) reversed the inhibitory effect of celecoxib according to dose. VEGF level stimulated with $20 \mathrm{ng} / \mathrm{ml}$ lipopolysaccharide (LPS) acted as a positive control (G). Results are expressed as mean (SEM) in a representative of three separate experiments. The error bar indicates the standard error calculated from triplicate samples in a representative experiment. ${ }^{*} \mathrm{p}<0.05$.

cultured macrophages, which in turn stimulates $\mathrm{PGE}_{2}$, and culminates in VEGF release.

\section{DISCUSSION}

In the present study, we demonstrated for the first time that MCP-1 stimulates COX-2 expression in human macrophages isolated from peripheral blood and cultured in vitro. In addition, MCP-1 stimulated VEGF release via a COX-2/PGE autocrine/paracrine pathway in these isolated macrophages. Furthermore, we found that MCP-1 expression levels were higher in adenomas than in normal colonic mucosa and limited exclusively to adenoma epithelial cells. MCP-1 expression levels increased with degree of dysplasia in adenomas: even epithelial cells exhibiting mild dysplasia expressed higher MCP-1 levels than normal colonic epithelium in the same patient. In contrast, COX-2 expression was found only in macrophages immediately beneath epithelial cells of adenomas expressing MCP-1, in accord with previous studies. ${ }^{12} 1324$ Therefore, these results raise the interesting possibility that endogenous MCP-1 release from adenoma epithelial cells is involved in COX-2 induction and subsequent $\mathrm{PGE}_{2}$ and VEGF release in macrophages infiltrating adenoma. Several lines of evidence suggest that COX-2 expressed in macrophages infiltrating the lamina propria might play a crucial role in the growth and progression of colorectal adenoma. Firstly, macrophages migrating into the lamina propria beneath intestinal polyps of mice bearing $A P C$ gene mutations show COX-2 expression, and COX-2 gene targeting in these mice dramatically decreases both polyp number and size. ${ }^{14}$ Secondly, cancer cells transplanted into wild-type mice grow more rapidly than those transplanted into $C O X-2$ gene knockout mice, suggesting that interstitial cells expressing COX-2 in the periphery of cancer cells are crucial for cancer cell growth. ${ }^{25}$ Thirdly, COX-2 expression was found in macrophages following their migration into the lamina propria of colonic adenomas in humans, and in human FAP, celecoxib, a selective COX-2 inhibitor, has been shown to prevent colorectal adenoma from progressing into adenocarcinoma. ${ }^{26}$ Therefore, to understand each step in the evolution of adenoma into carcinoma of the colon, it is essential to first clearly understand the adenoma epithelial and interstitial cell to cell interactions.

However, to date, the exact mechanism through which macrophages are first stimulated into migrating into the lamina propria of adenomas, and there induced to express COX-2, remains unknown. Recently, one possible candidate as a macrophage COX-2 inducer was isolated from conditioned media in a colon cancer cell line. The study suggested that, in the tumour microenvironment, mucins produced by colon cancer cells are involved in the initial induction of COX-2. ${ }^{27}$ However, it is not clear whether epithelial cells of adenomas do in fact secrete such mucins. Thus the study did not necessarily explain why macrophages migrate into the lamina propria of colonic adenoma and there express COX-2. However, in the present study, we found that, among chemokines known to have monocyte chemoattractant activity, including MCP-1, MIP- $1 \alpha$, MIP- $1 \beta$, and RANTES, MCP-1 alone showed higher expression levels in adenoma epithelial cells than in normal epithelial cells, in the same patient. Furthermore, when we cultured these tissue samples, we found that, here too, MCP-1 was synthesised at higher concentrations in adenomas than in normal colonic mucosa. MCP-1 is known as the most potent chemoattractant involved in macrophage migration. ${ }^{18}$ From these data we can speculate that MCP-1 is involved, not only in macrophage migration into the lamina propria bordering epithelial cells in adenomas, but also in induction of COX-2.

Although the exact mechanism through which COX-2 promotes tumorigenesis remains unknown, increasing evidence shows that COX-2 is involved in the promotion of angiogenesis in a variety of tumours: a number of growth factors, including angiogenic growth factors such as basic fibroblast growth factor and VEGF, ${ }^{28-31}$ have been shown to be released from colon cancer cells via a COX-2 dependent pathway. In addition, a close association between macrophage infiltration and microvessel density has been shown in a number of tumours, such as in melanomas, ${ }^{32}$ gliomas, ${ }^{33}$ cervical cancer, ${ }^{34}$ gastric cancer, ${ }^{35}$ oesophageal cancer, ${ }^{36}$ and breast cancer, ${ }^{37}$ suggesting that both COX-2 and macrophages may be important in promoting angiogenesis and tumour growth. Furthermore, PGE has been shown to induce VEGF production in U937 cells, a human macrophage model. ${ }^{38}$

In the present study, we found that MCP-1 stimulated both COX-2 expression and VEGF release in human macrophages. MCP-1 stimulated VEGF release from macrophages was inhibited in the presence of a selective COX-2 inhibitor. Reversal of this inhibition on addition of exogenous $\mathrm{PGE}_{2}$ suggests that, in macrophages, $\mathrm{PGE}_{2}$ is a proximate signal for MCP- 1 stimulated VEGF release. It is well known that VEGF is a key factor in angiogenesis, contributing to colorectal tumour growth. ${ }^{39} 40$ Therefore, our data imply that MCP-1 expressed in these adenoma epithelial cells might be, at least in part, involved in the production of VEGF by macrophages attracted into the subepithelial lamina propria, thereby contributing to tumour growth in the colon. However, we should note that neither MCP-1 stimulation nor celecoxib inhibition of VEGF release differed much from that seen at levels induced by FCS stimulation. Thus VEGF release from adenoma macrophages in vivo may also be regulated by other yet to be identified factors, in addition to the MCP-1/COX-2 pathway.

We found in the present study that adenoma tissue samples, when cultured for three hours, synthesised more MCP-1 protein than normal colonic mucosa samples, suggesting that MCP-1 mRNA expression and its translation into MCP-1 protein might also be higher in adenoma than in 
normal colonic mucosa. Nevertheless, it has yet to be determined what regulates MCP-1 expression in adenoma epithelial cells. In mice, $A P C$ gene mutations alone induce intestinal polyposis ${ }^{41}$ where COX-2 expressing macrophages can be seen in the polyp subepithelium. ${ }^{24}$ Similarly, even mild dysplasia adenoma showed higher levels of MCP-1 expression than normal colonic mucosa in the same patient, suggesting that any gene mutation involved in induction of adenomas might also be linked to MCP-1 expression in humans. However, more work is clearly required to identify the mechanism through which MCP-1 expression is induced in epithelial cells, and to elucidate the actual interaction between adenoma epithelial MCP-1, macrophage migration, and COX-2 expression in human colorectal adenoma.

\section{Authors' affiliations}

S Tanaka, A Tatsuguchi, S Futagami, K Gudis, K Wada, T Seo, K Mitsui, M Yonezawa, K Nagata, S Fujimori, T Tsukui, T Kishida, C Sakamoto, Third Department of Internal Medicine, Nippon Medical School, Tokyo, Japan

Conflict of interest: None declared.

\section{REFERENCES}

1 Chan AT, Giovannucci EL, Schernhammer ES, et al. A prospective study of aspirin use and the risk for colorectal adenoma. Ann Intern Med 2004; 140:157-66.

2 Thun MJ, Namboodiri MM, Heath CW Jr. Aspirin use and reduced risk of fatal colon cancer. N Engl J Med 1991;325:1593-6.

3 Giovannucci E, Egan KM, Hunter DJ, et al. Aspirin and the risk of colorectal cancer in women. N Engl J Med 1995;333:609-14.

4 Smalley W, Ray WA, Daugherty J, et al. Use of nonsteroidal antiinflammatory drugs and incidence of colorectal cancer: a population-based study. Arch Intern Med 1999;159:161-6.

5 Benamouzig R, Deyra J, Martin A, et al. Daily soluble aspirin and prevention of colorectal adenoma recurrence: one-year results of the APACC trial. Gastroenterology 2003;125:328-36.

6 Baron JA, Cole BF, Sandler RS, et al. A randomized trial of aspirin to prevent colorectal adenomas. N Engl J Med 2003;348:891-9.

7 Tangrea JA, Albert PS, Lanza E, et al. Non-steroidal anti-inflammatory drug use is associated with reduction in recurrence of advanced and non-advanced colorectal adenomas (United States). Cancer Causes Control 2003;14:403-11.

8 Sandler RS, Halabi S, Baron JA, et al. A randomized trial of aspirin to prevent colorectal adenomas in patients with previous colorectal cancer. N Engl J Med 2003;348:883-90.

9 Waddell WR, Ganser GF, Cerise EJ, et al. Sulindac for polyposis of the colon. Am J Surg 1989;157:175-9.

10 Waddell WR, Loughry RW. Sulindac for polyposis of the colon. J Surg Oncol 1983;24:83-7.

11 Eberhart CE, Coffey RJ, Radhika A, et al. Up-regulation of cyclooxygenase 2 gene expression in human colorectal adenomas and adenocarcinomas. Gastroenterology 1994;107:1183-8.

12 Bamba H, Ota S, Kato A, et al. High expression of cyclooxygenase-2 in macrophages of human colonic adenoma. Int J Cancer 1999;83:470-5.

13 Chapple KS, Cartwright EJ, Hawcroft G, et al. Localization of cyclooxygenase2 in human sporadic colorectal adenomas. Am J Pathol 2000;156:545-53.

14 Oshima M, Dinchuk JE, Kargman SL, et al. Suppression of intestinal polyposis in Apc delta716 knockout mice by inhibition of cyclooxygenase 2 (COX-2). Cell 1996;87:803-9.

15 Oshima M, Murai N, Kargman S, et al. Chemoprevention of intestinal polyposis in the Apcdelta716 mouse by rofecoxib, a specific cyclooxygenase2 inhibitor. Cancer Res 2001;61:1733-40.

16 Chapple KS, Scott N, Guillou PJ, et al. Interstitial cell cyclooxygenase-2 expression is associated with increased angiogenesis in human sporadic colorectal adenomas. J Pathol 2002;198:435-41.

17 Roth SJ, Carr MW, Springer TA. C-C chemokines, but not the C-X-C chemokines interleukin-8 and interferon-gamma inducible protein-10 stimulate transendothelial chemotaxis of T lymphocytes. Eur J Immunol 1995;25:3482-8

18 Fuentes ME, Durham SK, Swerdel MR, et al. Controlled recruitment of monocytes and macrophages to specific organs through transgenic expression of monocyte chemoattractant protein-1. J Immunol 1995; 155:5769-76.

19 Gelbmann CM, Leeb SN, Vogl D, et al. Inducible CD40 expression mediates NFkappaB activation and cytokine secretion in human colonic fibroblasts. Gut 2003:52:1448-56.

20 Miura S, Tatsuguchi A, Wada K, et al. Cyclooxygenase-2-regulated vascular endothelial growth factor release in gastric fibroblasts. Am J Physiol Gastrointest Liver Physiol 2004;287:G444-51.

21 MacNaughton WK, Cushing K. Role of constitutive cyclooxygenase-2 in prostaglandin-dependent secretion in mouse colon in vitro. J Pharmacol Exp Ther 2000;293:539-44.

22 Williams CS, Watson AJ, Sheng $\mathrm{H}$, et al. Celecoxib prevents tumor growth in vivo without toxicity to normal gut: lack of correlation between in vitro and in vivo models. Cancer Res 2000;60:6045-51.

23 Mizuno H, Sakamoto C, Matsuda K, et al. Induction of cyclooxygenase 2 in gastric mucosal lesions and its inhibition by the specific antagonist delays healing in mice. Gastroenterology 1997; 112:387-97.

24 Hull MA, Booth JK, Tisbury A, et al. Cyclooxygenase 2 is up-regulated and localized to macrophages in the intestine of Min mice. Br J Cancer 1999;79:1399-405.

25 Williams CS, Tsujii M, Reese J, et al. Host cyclooxygenase-2 modulates carcinoma growth. J Clin Invest 2000;105:1589-94.

26 Steinbach G, Lynch PM, Phillips RK, et al. The effect of celecoxib, a cyclooxygenase-2 inhibitor, in familial adenomatous polyposis. N Engl I Med 2000;342:1946-52.

27 Inaba T, Sano H, Kawahito Y, et al. Induction of cyclooxygenase-2 in monocyte/macrophage by mucins secreted from colon cancer cells. Proc Natl Acad Sci U S A 2003;100:2736-41.

28 Tabara H, Kohno H, Dhar DK, et al. Concurrent expression of angiogenic growth factors and neovascularization during tumourigenesis in colorectal carcinoma patients. Acta Oncol 2001;40:622-8.

29 Tatsuguchi A, Matsui K, Shinji Y, et al. Cyclooxygenase- 2 expression correlates with angiogenesis and apoptosis in gastric cancer tissue. Hum Pathol 2004;35:488-95.

30 Ghosh AK, Hirasawa N, Niki H, et al. Cyclooxygenase-2-mediated angiogenesis in carrageenin-induced granulation tissue in rats. J Pharmacol Exp Ther 2000;295:802-9.

31 Leung WK, To KF, Go MY, et al. Cyclooxygenase-2 upregulates vascular endothelial growth factor expression and angiogenesis in human gastric carcinoma. Int J Oncol 2003;23:1317-22.

32 Shimizu T, Abe R, Nakamura $H$, et al. High expression of macrophage migration inhibitory factor in human melanoma cells and its role in tumor cell growth and angiogenesis. Biochem Biophys Res Commun 1999;264:751-8.

33 Nishie A, Ono M, Shono T, et al. Macrophage infiltration and heme oxygenase- 1 expression correlate with angiogenesis in human gliomas. Clin Cancer Res 1999;5:1107-13.

34 Davidson B, Goldberg I, Gotlieb WH, et al. Macrophage infiltration and angiogenesis in cervical squamous cell carcinoma--clinicopathologic correlation. Acta Obstet Gynecol Scand 1999;78:240-4.

35 Ohta M, Kitadai Y, Tanaka S, et al. Monocyte chemoattractant protein-1 expression correlates with macrophage infiltration and tumor vascularity in human gastric carcinomas. Int J Oncol 2003;22:773-8.

36 Ohta M, Kitadai Y, Tanaka S, et al. Monocyte chemoattractant protein-1 expression correlates with macrophage infiltration and tumor vascularity in human esophageal squamous cell carcinomas. Int J Cancer 2002;102:220-4.

37 Leek RD, Lewis CE, Whitehouse R, et al. Association of macrophage infiltration with angiogenesis and prognosis in invasive breast carcinoma. Cancer Res 1996;56:4625-9.

38 Bamba H, Ota S, Kato A, et al. Effect of prostaglandin El on vascular endothelial growth factor production by human macrophages and colon cancer cells. J Exp Clin Cancer Res 2000;19:219-23.

39 Cianchi F, Cortesini C, Bechi P, et al. Up-regulation of cyclooxygenase 2 gene expression correlates with tumor angiogenesis in human colorectal cancer. Gastroenterology 2001;121:1339-47.

40 White JD, Hewett PW, Kosuge D, et al. Vascular endothelial growth factor-D expression is an independent prognostic marker for survival in colorectal carcinoma. Cancer Res 2002;62:1669-75.

41 Oshima M, Oshima H, Kitagawa K, et al. Loss of Apc heterozygosity and abnormal tissue building in nascent intestinal polyps in mice carrying a truncated Apc gene. Proc Natl Acad Sci U S A 1995;92:4482-6. 